\title{
Picture perception in birds: Perspective from primatologists
}

\author{
Joël Fagot \& Carole Parron \\ CNRS-Université de Provence
}

\begin{abstract}
In their target article, Weisman and Spetch (2010) question the validity of pictures to present real things to birds, mostly because pictures are primarily made for the human eye, and not for the eye of birds with different functional properties. Here, we argue that this issue of picture validity is similarly critical for primatologists, even when they study the "higher" nonhuman primates with a more similar visual system, and emphasize cognitive limitations in referential abilities that may be an important source of differences in picture processing modes between human and animals.
\end{abstract}

Keywords: picture, visual cognition, monkey

In their target paper, Weisman and Spetch (2010) review the literature on picture perception in birds and adequately question the validity of pictorial stimuli (photographs, digitized pictures, and movies) to present real objects or scenes to these animals. In their review, they raise the important issue that with the current technology, pictures are primarily designed to be perceived by human eyes and might therefore, not be well adapted to birds possessing a different visual system. They document the risk for anthropocentric errors in experimental research using pictures with birds, and call for new empirical evidence showing a correspondence between the perception of pictures and the perception of objects in birds. Despite the widespread use of pictures in animal psychology, investigators have rarely questioned the realistic nature of pictures and their ecological validity. In that respect, Weisman and Spetch's paper (2010) is among the very few to explicitly do so (see also Cabe, 1976, Fagot 2000). They must be applauded for bringing back this important issue to the attention of the field. In general, we are supportive of their position that a greater care must be given to the use of pictures in experimental animal research. However, consideration of the primate literature suggests that Joël Fagot and Carole Parron, Laboratory of Cognitive Psychology, CNRS-Université de Provence, Marseille France.

Correspondence concerning this article should be addressed to Joël Fagot at joel.fagot@univ-provence.fr. limitation in picture perception by animals is not completely accounted for by differences in just visual systems, but may also reflect cognitive limitations, beyond perception.

\section{Nonhuman primates do not have a human-like vision}

In conventional photography as well as in electronic systems, such as televisions and computers, spots of red, green and blue light are added together to reproduce a broad array of colors. Combination of these three focal colors matches the functioning of our visual system that contains three types of cones selectively sensitive to the red, green and blue color bands. Weisman and Spetch (2010) emphasize the difference between the vision of birds and that of primates in questioning the validity of pictures for birds. One critical difference is that the avian retina (especially in pigeons, the most frequently tested species) contains at least four types of color receptors (see also Delius, Emmerton, Hoërster, Jäger \& Ohstein, 2000), instead of the three in humans. In addition, the flicker fusion point is higher in pigeons than in humans, which may be a source of difficulty when computerized displays are used. Although the authors do not discuss the case of species other than birds, we note that many nonhuman primates also have a visual system very different from that of humans. Most prosimians, if not all, are either mono- or dichromatic and 
therefore, have a very limited ability for color vision, unlike humans. New world monkeys may see colors, but their color vision is surprisingly variable across individuals. Some of them are dichromatic and others are trichromatic (Jacobs, 1996). For instance, in capuchin monkeys, color vision is gender dependent with only females distinguishing the reds (Gomes, Pessoa, Tomaz \& Pessoa, 2002). Therefore, the primatologists working with prosimians and new world monkeys often encounter the same problems as bird researchers, when they use pictures in their experimental designs. Psychophysical studies conducted in a phylogenetic perspective show that a human like visual system emerged in catharrhine monkeys (cercopithecoidea and hominoidea super families). These primates are trichomatic and their cone receptors have the wavelength sensitivities comparable to humans (Jacobs \& Deagan, 1999). They also have similar flicker sensitivity, and similar contrast sensitivity functions or visual acuities (De Valois \& De Valois, 1988), suggesting that the development of visual systems has reached a relative plateau in these nonhuman primate species and in humans (Fobes \& King, 1982). Following Weisman and Spetch, one would expect that those nonhuman primates may process the pictures as humans do, but that conclusion would neglect the contribution of more cognitive factors to picture perception.

\section{Processing of pictures as referents}

Pictures are complex and ambiguous stimuli. They are two-dimensional flat objects (i.e., the picture) that represent three-dimensional objects or scenes in the real world. Thus, from the human perspective, a picture is more than the object. It is a representation. Being able to process a picture as a representation of real objects requires several kinds of competencies. First, the perceiver must be able to perceive the three-dimensionality of the pictorial object by considering the physical properties of the picture (e.g. in terms of color, texture, contour or motion cues, Desimone, Albright, Gross, \& Bruce, 1984). Birds, prosimians and some new world monkeys may diverge from humans in that first process due to different visual systems. By contrast, having identical visual systems likely promotes similar processing of the low level features available in the pictures. However, that first component is not sufficient for similar picture processing between humans and animals, as object identification must also take place. This second process is not obvious at all. Object identification must be achieved in spite of the perceptual differences between the object and its pictures. Importantly, pictures are missing cues available in the real objects, such as stereoscopic depth. They also contain extra cues that are not present in the real world, such as the reflectance of the photographic paper or the flatness of the screen. Therefore, object identification must occur in a context where some relevant information is missing or presented in conjunction with irrelevant information that may emphasize the two-dimensional character of the picture. We suspect that species with similar visual psychophysics do not pass this second stage of object identification equally well. There might also be variations across members of the same species. Some species or individuals may particularly attend to object related cues, while the other may attend, in priority, to the distracting cues, suggesting that the picture is a flat object. Third, even if we assume that the species of interest can recognize the objects on the picture, it is not guaranteed that the picture will be treated as a representation of the object, as humans commonly do. Being able to process the picture as a picture requires referential abilities that might not be equally present in all primate species, even if they belong to the catarrhine group with a visual system possessing the same functional characteristics as that of humans. Therefore, cognitive limitations might be additional sources of variations in the way animals and humans process pictures. Therefore, cognitive limitations in the way humans and other animals process pictures are additional sources of variation between species.

\section{Variabilities in picture processing modes}

In our view, what is really missing in the field is a framework for describing differences in picture processing. Earlier, we tentatively distinguished among three levels of pictures processing which were coined "independence", "confusion" and "equivalence" (Fagot, Martin-Malivel, \& Dépy, 2000; Fagot, Bonté \& Parron, 2009, Fagot, Thompson \& Parron, 2010, see also Persson, 2008 for a similar theoretical attempt). "Independence" refers to when the subject fails to identify objects in pictures. In that case, the perceiver has no other choice than to attend to the low level pictorial features relevant to the test situation, such as color cues in a categorization task (e.g. D'amato \& Van Sant, 1988). "Confusion" refers to a situation when the object is properly identified on the picture but the perceiver treats the photographs as if they were functional and physical exemplars of the referent. In other words, the picture is not a picture from the standpoint of the perceiver; it is the "real" object. One good demonstration of a confusion mode of processing is when the monkey eats the picture of a banana as it would with a real banana (Parron, Call \& Fagot, 2008). Finally, the "equivalence" characterizes a functional equivalence between the picture and its content, although the subject is aware that the object and the pictures are two different objects. In that case, the picture becomes a representational substitute of its referent (Tanaka, 2007; Fagot, Malivel \& Dépy, 2000; Fagot, Thompson \& Parron, 2010). 


\section{Picture perception: A dynamic process}

Most humans process pictures in an equivalence mode, but this ability is not innate and develops following a developmental trend. For instance, nine-month-old children suck the nipple of a pictorial baby bottle, suggesting a confusion mode of processing at that age (Deloache, Pierroutsakos, Uttal, Rosengren, \& Gottlieb, 1998). This behavior vanishes in older infants probably as a result of both maturation and repeated experience with pictures (e.g. Deloache, 2004). At a later age (15-18 months), children become "symbol minded" and use pictures as representations. They play with books, extend newly learned labels from real objects to depicted objects, and transfer information from drawing books and the real world (Ganea, Pickard \& Deloache, 2008). Pictures are also cultural artifacts (Persson, 2008), and their interpretation varies as a function of culture or prior exposure to pictorial stimuli. Early anthropologists from the late 19th century reported that people from pictorially naïve remote cultures do not spontaneously perceive objects or persons in pictures, but did so after they had the equivalence between the picture and its referent explained (see Deregowski, 2000). Developmental and cross-cultural studies both suggest that the ability to read pictures as referent results from a learning process.

Unfortunately, most studies using pictures with nonhuman primates provide no decisive cues as to their picture processing mode (Fagot, 2000). Like researchers working with birds, primatologists often implicitly assume that their animals perceive a correspondence between the picture and its referent, and use the picture accordingly. However, there is good evidence that catarrhine monkeys (e.g. MartinMalivel \& Fagot, 2001, Perrett \& Mistlin, 1990) or apes (e.g. Parron et al, 2008) often process the picture in an independence or confusion mode. Clear-cut demonstrations of an equivalence (referential) mode of picture processing are virtually absent in monkeys, but are more convincing in apes. Persson (2008) who has extensively reviewed this evidence in apes concludes that there seems to be individual apes that can decode pictures in an equivalence mode (pictorial mode in his terms, p. 201). Interestingly, this evidence is mostly restricted to the so-called languagetrained chimpanzees, such as Viki (Hayes \& Hayes, 1953), Kanzi (Savage-Rumbaugh, Shanker \& Taylor, 1998) and Aï (Itakura, 1994, Matsuzawa, 2003), suggesting that language training may encourage this type of processing in apes.

In conclusion, we definitely support Weisman and Spetch's (2010) claim for a more cautious use of pictures in experimental designs, even by those of us working with monkeys and apes. We would further add that variations in picture processing between humans and other animals cannot be explained solely by differences in perceptual systems. Even subjects with identical visual systems may process pictures differently, either because they are not similarly proficient to solve referential cognition problems, or because they have not been exposed enough to pictures to develop a referential form of process.

\section{References}

Cabe, P. A. (1976). Transfer of discrimination from solid objects to pictures by pigeons: A test of theoretical models of pictorial perception. Perception \& Psychophysics, 19, 545-550. http://psycnet.apa.org/index.cfm?fa $=$ search.disp layRecord\&uid=1976-27304-001

D'Amato, M. R., \& Van Sant, P. (1988). The person concept in monkeys (Cebus apella). Journal of Experimental Psychology: Animal Behavior Processes, 14, 43-55. doi:10.1037/0097-7403.14.1.43

Delius, J. D., Emmerton, J., Horster, W., Jager, R., \& Ostheim, J. (2000). Picture-object recognition in pigeons. In (Ed.) J. Fagot, Picture perception in animals, 1-35. London: Psychology Press.

DeLoache, J. S. (2004). Becoming symbol-minded. Trends in Cognitive Science, 8, 66-70. doi: 10.1016/j. tics.2003.12.004 PMid:15588810

DeLoache, J. S., Pierroutsakos, S. L., Uttal, D. H., Rosengren, K. S., \& Gottlieb, A. (1998). Grasping the Nature of Pictures. Psychological Science, 9, 205-210. doi: $\underline{10.1111 / 1467-9280.00039}$

Deregowski, J. B. (2000). Pictorial perception: individual and group differences within the human species. In: Fagot, J. (Ed.), Picture Perception in Animals. Psychology Press, London, pp. 397-429.

Desimone, R., Albright, T. D., Gross, C. G., \& Bruce, C. (1984). Stimulus selective properties of inferior temporal neurons in the macaque. Journal of Neuroscience, 4, 2051-2062. PMid:6470767

De Valois, R., \& De Valois, K. (1988). Spatial vision. New York: Oxford University Press.

Fagot, C., Bonté, E., \& Parron, C. (2009). Concept of uprightness in baboons: Assessment with pictures of realistic scenes. Animal Cognition, 12, 369-379. doi:10.1007/s10071-008-0196-6 PMid:18925421

Fagot, J., 2000. Picture Perception in Animals. Psychology Press, London, pp. 447.

Fagot, J., Martin-Malivel, J., \& Dépy, D. (2000). What is the evidence for an equivalence between objects and pictures in birds and nonhuman primates. In Fagot, J. (Ed.), Picture Perception in Animals. Psychology Press, London, pp. 295-320.

Fagot, J., Thompson, R., \& Parron, C. (2010). How to read a picture: Lessons from nonhuman primates. PNAS, 107, 519-520. doi:10.1073/pnas.0913577107 PMid:20080714 
Fobes, J. L., \& King, J. E. (1982). Vision: The dominant primate modality. In J.L. Fobes \& J.E. King (Eds), Primate Behavior (pp.219-243). New-York: Academic Press.

Ganea P. A., Pickard P., \& DeLoache J. (2008). Transfer between picture books and the real world by very young children. Journal of Cognition and Development, 9, 4666. doi:10.1080/15248370701836592

Gomes, U. R., Pessoa, D. M. A., Tomaz, C., \& Pessoa, V. (2002). Color vision perception in the capuchin monkey (Cebus apella): a re-evaluation of procedures using Munsell papers. Behavioural Brain Research, 129, 153157.doi:10.1016/S0166-4328(01)00335-7

Hayes, K. J., \& Hayes, C. (1953). Picture perception in a home-raised chimpanzee. Journal of Comparative and Physiological Psychology, 46, 470-474. doi: 10.1037/

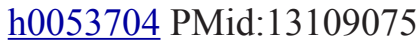

Itakura, S. (1994). Recognition of line-drawing representations by a chimpanzee (Pan troglodytes). The Journal of General Psychology, 121, 189-197. PMid:7964661

Jacobs, G. H. (1996). Primate photopigments and primate color vision. PNAS, 93, 577-581. doi:10.1073/ pnas.93.2.577

Jacobs, G. H., \& Deagan II, J. F. (1999). Uniformity of colour vision in Old World monkeys. Proceedings of the Royal Society: Biological Sciences, 266, 20232028. doi:10.1098/rspb.1999.0881 PMid:10584339 PMCid:1690314

Martin-Malivel, J., \& Fagot, J. (2001). Perception of pictorial human faces by baboons: Effects of stimulus orientation on discrimination performance. Animal Learning \& Behavior 29, 10-20. http://lb.psychonomic-journals.org/ content/29/1/10.short

Matsuzawa, T. (2003). The Ai project: Historical and ecological contexts. Animal Cognition, 6, 199-211. doi:10.1007/s10071-003-0199-2 PMid:14566577

Parron, C., Call, J., \& Fagot, J. (2008). Behavioural responses to photographs by pictorially naïve baboons (Papio anubis), gorillas (Gorilla gorilla) and chimpanzees (Pan troglodytes). Behavioural Processes, 78, 351-357. doi:10.1016/j.beproc.2008.01.019 PMid:18342457

Perrett, D. I., \& Mistlin, A. J. (1990). Perception of facial characteristics by monkeys. In: Stebbins,W.C., Berkley, M.A. (Eds.), Comparative Perception: Complex Signals, 2, 187-215. http://psycnet.apa.org/ psycinfo/1990-97504-006

Persson, T. (2008). Pictorial Primates: A Search for Iconic Abilities in Great Apes. Lund University Cognitive Studies, 136. http://swepub.kb.se/bib/swepub:oai:lup.lub. lu.se:938491?tab2=abs\&language $=$ en

Savage-Rumbaugh, S., Shanker, S. G., \& Taylor, T. J. (1998). Apes, Language, and the Human Mind. New York: Oxford University Press.
Tanaka, M. (2007). Recognition of pictorial representations by chimpanzees (Pan troglodytes). Animal Cognition, 10, 169-179. doi: 10.1007/s10071-006-0056-1 PMid:17171361

Weisman, R., \& Spetch, M. (2010) Determining when birds perceive correspondence between pictures and objects: a critique. Comparative Cognition and Behavior Reviews, 5, 117-131. Retrieved from http://psyc.queensu.ca/ccbr/

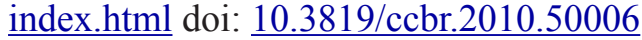

